\title{
Strategies for Better Fuel Economy, Light Weighting, and Friction Reduction in Cylinder Components of IC Engines
}

\author{
R. Mahadevan
}

\begin{abstract}
Automotive OEMs have been working on various technologies for reducing $\mathrm{CO}_{2}$ emissions and improving fuel economy in their vehicles. Among the strategies that are being employed relating to the IC Engine, light weighting, and friction reduction are the two areas that have received special attention. As the Piston assembly has a direct influence on the friction power of the engine, attempts have been made to reduce the reciprocating mass and improve friction through innovation in design materials and manufacturing processes. Improvements in design and manufacture of pistons and new surface coatings for Pistons \& Rings have been able to significantly reduce friction and improve fuel economy. Some of these developments are discussed in this paper.
\end{abstract}

Keywords $\mathrm{CO}_{2}$ emission $\cdot$ Cylinder components - Surface coating - Engine friction - Manufacturing process

R. Mahadevan $(\square)$

India Pistons Limited, Chennai, India

e-mail: rm@indiapistons.com 